IRA-International Journal of Technology \& Engineering ISSN 2455-4480

Proceedings of the International Conference on Science \& Engineering for Sustainable Development (2017)

Pg. no.318-326

Published by: Institute of Research Advances https://research-advances.org/index.php/IRAJTE

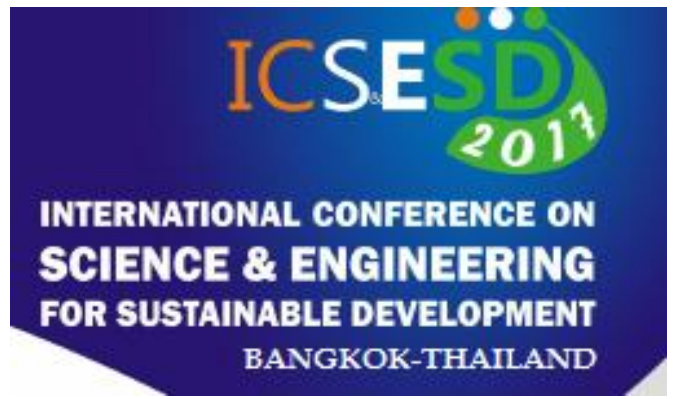

\title{
Selected Al Alloy and Analyses of its Decrease Machinability
}

\author{
Kusmierczak, Sylvia ${ }^{1}$, Naprstkova, Natasa ${ }^{2}$ \\ 1,2 Department of Technology and Material Science, Faculty of Production Technology \\ and Management, Jan Evangelista Purkyně University in Ústínad Labem, Pasteurova 1, \\ 40096 Ústínad Labem, Czech Republic.
}

(naprstkova@fvtm.ujep.cz, kusmierczak@fvtm.ujep.cz)

Type of Review: Originality Check \& Peer Review under the responsibility of the Scientific Committee of the Conference and The Institution of Engineers (India). DOI: http://dx.doi.org/10.21013/jte.ICSESD201730

How to cite this paper:
Sylvia, K., Natasa, N. (2017). Selected Al Alloy and Analyses of its Decrease Machinability.
Proceedings of the International Conference on Science \& Engineering for Sustainable
Development (2017), 318-326. doi: http://dx.doi.org/10.21013/ite.ICSESD201730

(C) International Conference on Science \& Engineering for Sustainable Development\& The Institution of Engineers (India).

\section{(cc) EY-NC}

This work is licensed under a Creative Commons Attribution-Non Commercial 4.0 International License subject to proper citation to the publication source of the work.

Disclaimer: The conference papers as published by the Institute of Research Advances (IRA) are the views and opinions of their respective authors and are not the views or opinions of the IRA. The IRA disclaims of any harm or loss caused due to the published content to any party. 
ABSTRACT

Aluminum alloys are frequently subjected to machining process and for this process is important their machinability, which depends on many factors. The Faculty of Production Technology and Management is often asked by companies with a request to solve a specific technical tasks. One of these tasks was the analysis of one specific aluminum alloy bath with worsened machinability. The rods from this alloy exhibited against assumption significantly worse chips during machining. That meant, of course, bad situation in area of machining tools. At the faculty were done analysis that could contribute to identifying the cause of the worsened machinability.

Keywords: alloy, aluminum, structure, analyses

\section{Introduction}

Aluminum alloys are frequently subjected to machining process and for this process is important their machinability, which depends on many factors. The main factors are working material, tool, lubrication or cooling etc. In frame of material it is its chemical composition and microstructure. Important is also the appropriate choice of cutting conditions, in which we machine the material. In the machining process there is generally required a delicate crumbly chip, which facilitates not only the handling, but also affects the costs of waste management. [1,2] This article was created at the request of one company to determine the reason for change in machinability aluminum alloy EN AW 6064, when part of one production batch has been returned under the complaint procedure, when this batch during machining showed just a schip in Fig. 1.

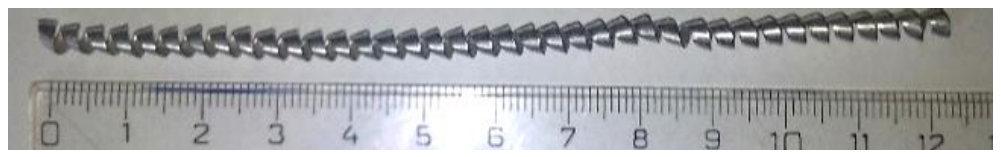

Fig. 1 Chip unsuitable for cutting process

\section{Experiment}

As mentioned above, the subject of examination was the cause of an inappropriate chip for one batch of alloy EN AW 6064. Experiment was realized for two aluminum rods with a diameter of $14 \mathrm{~mm}$ and a length of about $1 \mathrm{~m}$. These rods were delivered by contractor. Both rods were from above mentioned alloy EN AW 6064. The problem was the poor machinability oneof the rods, which the contracting authority justified by very long spiral chip, which was formed during machining. By contracting authority the rods were described as rod GOOD (OK) and rod BAD (NOK), see Fig. 2.

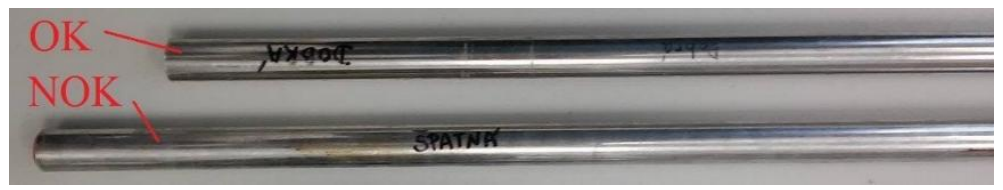

Fig. 2 Analysed rods

Before analyses was neccessery to prepare samples for microscopy analyses. Part of experimental material was machining, too. Samples for microscopy analyses were prepared by the usual metalograpfical procedure. Machining of samples was realized on the lathe EMCO MAT - 14 S. Cutting contitions are sumarrized in the Tab. 1. 
Tab. 1 Choice of cutting conditions and marking of samples

\begin{tabular}{|l|l|l|l|l|}
\hline \multicolumn{1}{|c|}{ Cutting conditions } & \multicolumn{2}{c|}{ roughing } & \multicolumn{2}{c|}{ finishing } \\
\hline Machining diameter $[\mathrm{mm}]$ & 14 & 14 & 11 & 11 \\
\hline Depth of cut $\mathrm{a}_{\mathrm{p}}[\mathrm{mm}]$ & 1.5 & 1.5 & 0.5 & 0.5 \\
\hline Feed $\mathrm{f}[\mathrm{mm} / \mathrm{rev}]$ & 0.25 & 0.25 & 0.25 & 0.25 \\
\hline Cutting speed $\mathrm{v}_{\mathrm{c}}[\mathrm{m} / \mathrm{min}]$ & 140 & 125 & 140 & 125 \\
\hline
\end{tabular}

\section{Methods of analysis}

To search for causes unsuitable chip forming rod was subjected to the following analyzes: chemical analysis, static tensile testaccording to ČSN EN 10 002-1, microscopic analysis of the unetched state using light microscopy, microscopic analysis of etched state using light microscopy, microscopic analysis using electron microscopy for idetification of particles, evaluation of surface roughness after machining according to ČSN EN ISO 4287,rating of chips according to STN ISO 3685, quantity of chips per $100 \mathrm{~g}$, stamping chips coefficient,hardness rating according to ČSN EN ISO 6507-1 and fracture analyses.

Chemical analysis was realized on the spectrometer BAS Q4 Tasman.

To determine the mechanical characteristics of the material was performed the static tensile test. [3, 4, 5]The results are shown in Tab. 2.

Tab. 1 Mechanical values of rods from alloys EN AW 6064A (OK and NOK)

\begin{tabular}{|c|c|c|c|}
\hline & $\mathbf{R}_{\mathbf{m}}[\mathbf{M P a}]$ & $\mathbf{R}_{\mathbf{p 0 , 2}}[\mathbf{M P a}]$ & $\mathbf{A}_{\mathbf{5}}[\mathbf{\%}]$ \\
\hline OK & 376 & 369 & 12.6 \\
\hline NOK & 365 & 357 & 10.6 \\
\hline
\end{tabular}

For microscopic analysis were prepared four samples from the rods OK and NOK in longitudinal and cross section. [6, 7]

First, the structure was analyzed in unetched condition.Samples were analyzed by light microscope Olympus LEXT OLS 3100.[8, 9]For samples OK (Fig. 3) we could observe uneven distribution of phases $\alpha$ and intermetallic phases. In cross section was possible to observe two types of phases that differed in size. Larger particles were intermetallic phases of the type BiAlMg, which have a positive effect on the machinability due to the low melting point of Bi. Furthermore, there were the polycomponent phases containing most of the alloying elements. These were the phases based on AlFeSiMg. In sample NOK in cross section we could observed uneven distribution of different phases (Fig. 4). In comparison with the sample OK the structure contained a smaller proportion of larger phases based on BiAlMg. Large particles were intermetallic phases AlBiMg, wherein the proportion of $\mathrm{Bi}$ in this phase was lower than the proportion in sample OK. Because the incidence and distribution of those phases significantly affect machinability alloys, it could be assumed that the smaller quantity of these had influence on the formation and in particular on the shape of the chip. Further, in the the sample NOK there found the intermetallic phases AlPbMg. These were small particles of about $2 \mu \mathrm{m}$. In sample NOK there was also possible to observe complex polycomponent phases with representation of most alloying elements. These were the phases based on $\mathrm{AlFeSiMgMnPbCu}$. In samples NOK there found a smaller number of phases based on $\mathrm{BiAlMg}$, it could be assumed that for this reason, this alloy will have a worse machinability than the sample OK. In sample OK in longitudinal section there were observed directed intermetallic phases in the forming direction (Fig. 5). In the Fig. 6were a longitudinal sectional structure of the sample NOK. When comparing a sample OK and NOK in longitudinal section, there could be observed diversity in the size of intermetallic phases. In sample OK could be observed large intermetallic phases, which were uniformly spaced and were approximately $50 \mu \mathrm{m}$. In sample NOK, the phases were smaller and irregularly distributed. Their size was about $30 \mu \mathrm{m}$. 


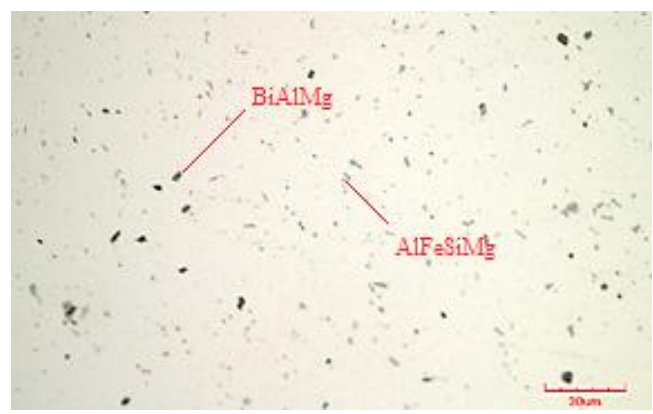

Fig. 3 Sample OK, cross section

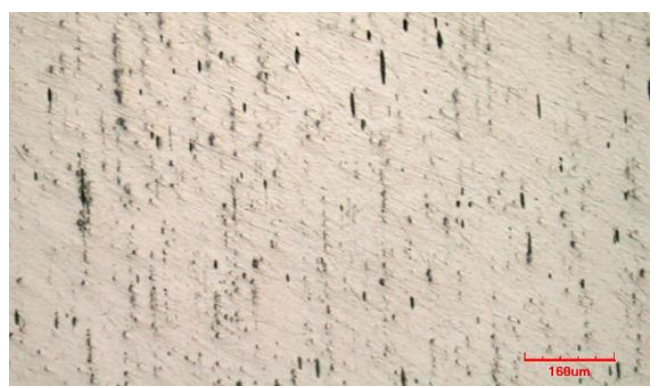

Fig. 5 Sample OK, longitudinal section

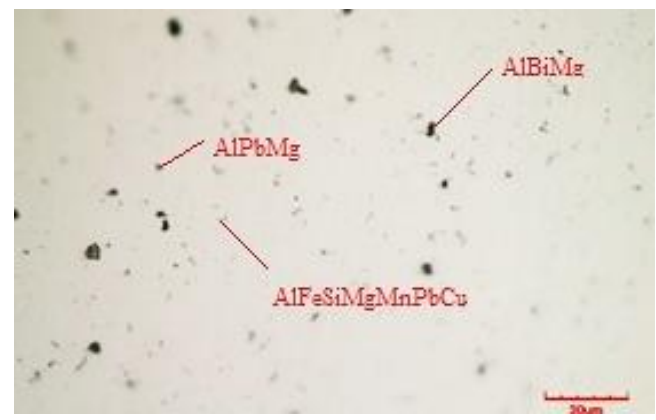

Fig. 4 Sample NOK, cross section

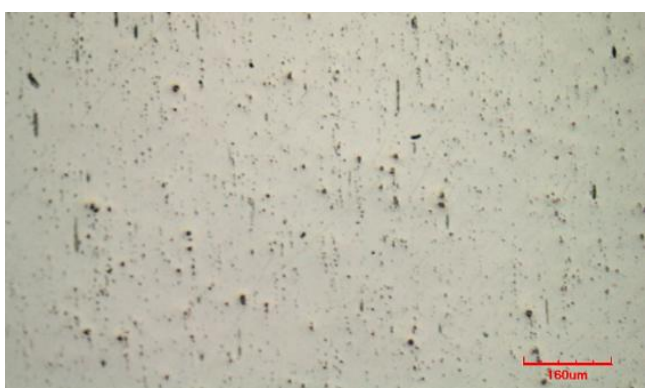

Fig. 6 Sample NOK, longitudinal section

Further, an analysis of the microscopic structure was realized in etched state. This analysis was performed in order to investigate grain size. Samples of material were etching by mixtures of acids and observed in polarized light with a light microscope Olympus BX51M.See Fig. 7 and Fig. 8.[10]

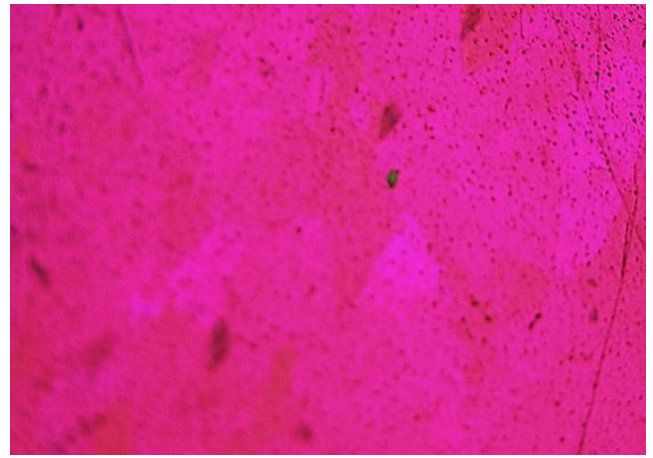

Fig. 7 Sample OK, mgn. 100x

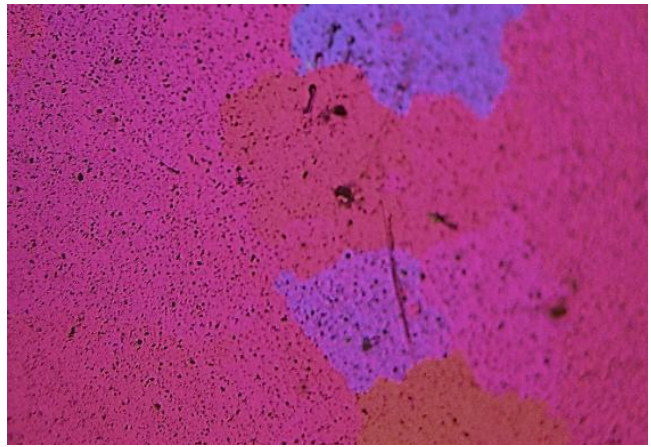

Fig. 81 Sample NOK, mgn. 100x

Next was analyses of some particles on an electron microscope Tescan Vega 3 using EDX analyzer BRUCKER 16. There were prepared two samples from bars OK and NOK for observation in cross section. The surface was grinded, polished and was etched. Selection of particles proceeded according to their characteristic size and shape.[10, 11, 12]

In sample OK was analyzed three particles. Fig. 9 shows one of them. In sample NOK were analyzed four particles. Fig. 10 shows one of them. For the first particle, according to the chemical composition it has been possible to say that this was an intermetallic phase based on AlPbMg. The size of the first particles was approximately $4 \mu \mathrm{m}$. The second analyzed particle was identified as an intermetallic phase based on AlBiMg. This particle was also great about $4 \mu \mathrm{m}$. Third particle had a similar chemical composition as 
the second particle. This was according to analysis the intermetallic phase based on $\mathrm{AlBiMg}$. The difference, however, was on its size. This particle was approximately half the size, was great about $2 \mu \mathrm{m}$.

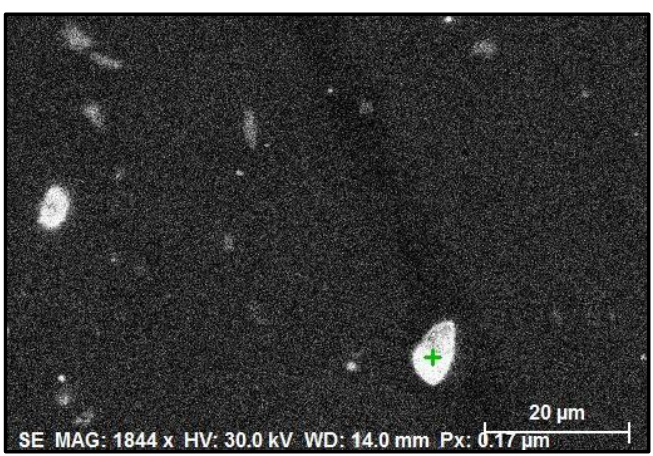

Fig. 9 Particle 2, sample OK

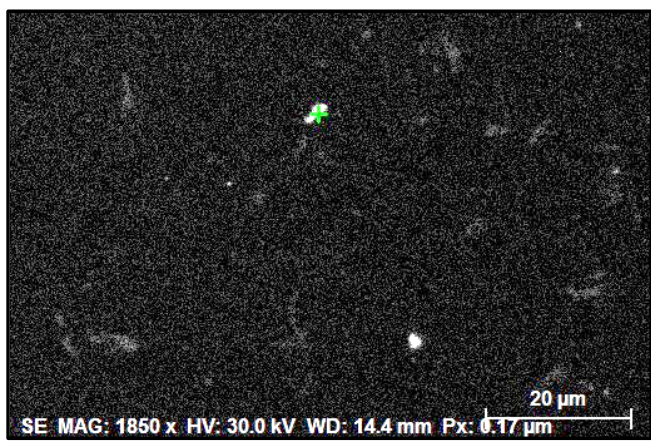

Fig. 10 Particle 2, sample NOK

Next was evaluated the obtained surface roughness Ra, Rz and Rt after machinig, how was mentioned above. Fig. 11 and 12 show examples of created graphs. During roughing roughness was slightly better for the alloy NOK, when finish machining the surface roughness were either the same or slightly better for the alloy OK.[13, 14]

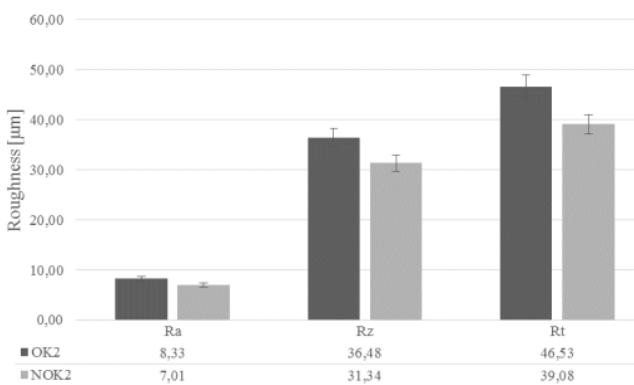

Fig. 11Comparison of surface roughness for samples OK2 and NOK2 - roughning

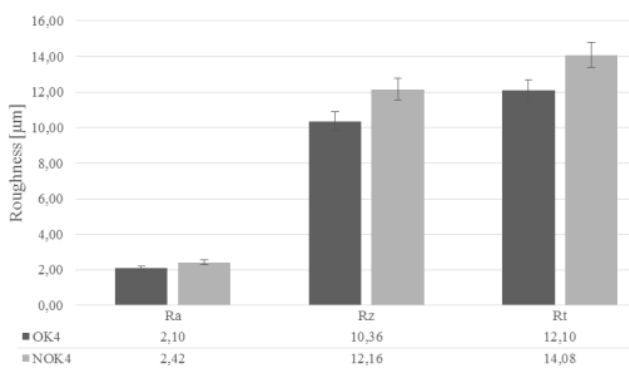

Fig. 12 Comparison of surface roughness for samples OK4 and NOK4 - finishing

There werealso evaluated chips which were obtained by machining under cutting conditions. Chip was evaluated visually, next according to the quantity of chips per $100 \mathrm{~g}$ and according to the stamping chips coefficient. Fig. 13 and 14 show samples of the chips after the machining alloys OK and NOK. Evaluation according to the number of chips per $100 \mathrm{~g}$ according to the company's internal process was carried out in a laboratory balance AND GF-200, which is measured with an accuracy of $0.001 \mathrm{~g}$. Fig. 15 and 16 show graphs obtained by measurements. [15]

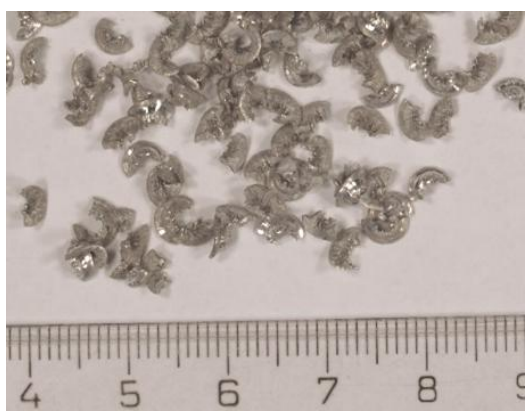

Fig. 13 Chips OK1, roughning

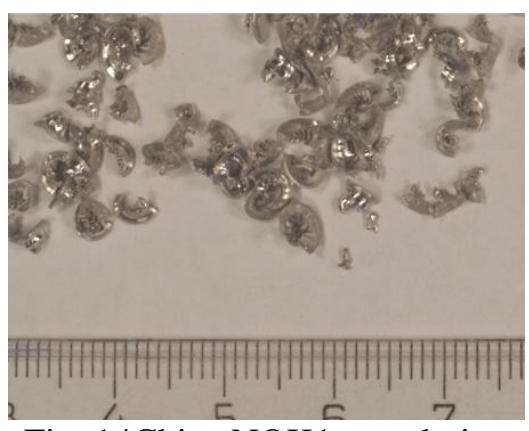

Fig. 14Chips NOK1, roughning 


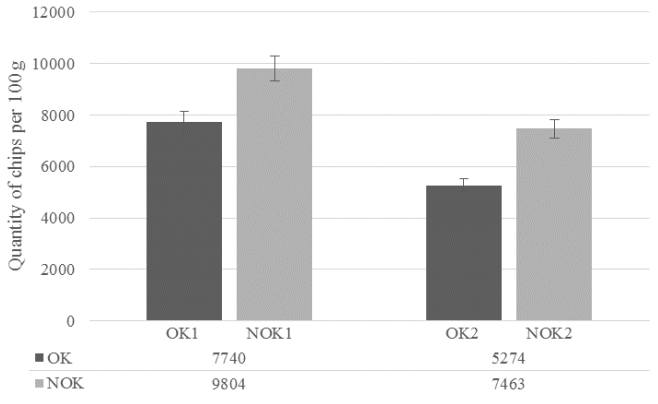

Fig. 15 Quantity of chips per 100g, roughing

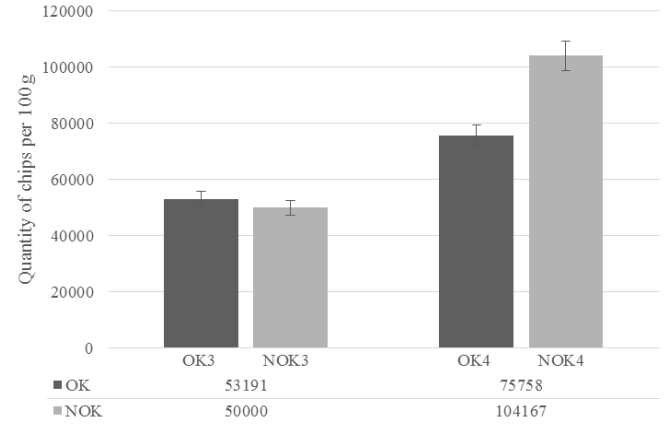

Fig. 16 Quantity of chips per $100 \mathrm{~g}$, finishing

Another measurement was the determining stamping chips coefficient. This has been implemented only for the roughing operations, because the finish machining originated chip which was difficult to measure. Fig. 17 shows graph with obtained results.

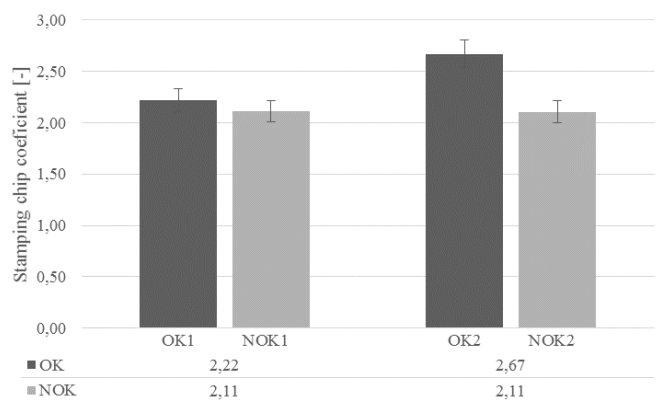

Fig. 17 Comparison of stamping chip coefficient for samples OK and NOK

The next measurements carried out in the evaluation irons OK and NOK were hardness measurements. Hardness test was chosen Vickers according to ČSN EN ISO 6507-1. Sample surface was ground and then polished. Was carried out ten measurements for each sample. The places of individual stitches were chosen randomly. The measured values are shown in the graph in Fig. 18.

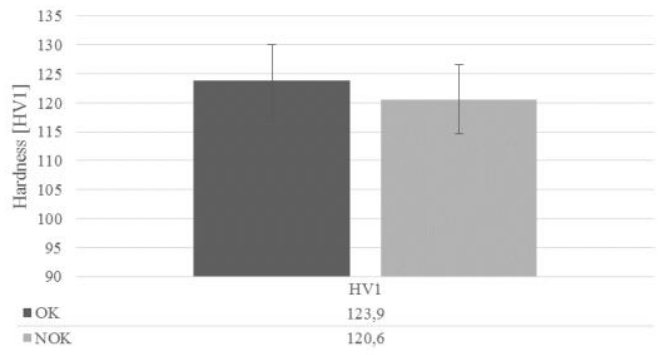

Fig. 18 Comparison of hardness for the samples OK and NOK

For fractograpfic analyses were made samples from rods OK and NOK. On the experimental samples was created notch and with using tensile test machine these samples were broked.The fracture surface was formed under the same conditions for the sample OK and NOK. Thenthesampleswereobserved on electron microscope Tescan Vega 3. On theFig. 19 and 20 there are picturesoffracture surgace forbothsamples.[16] 


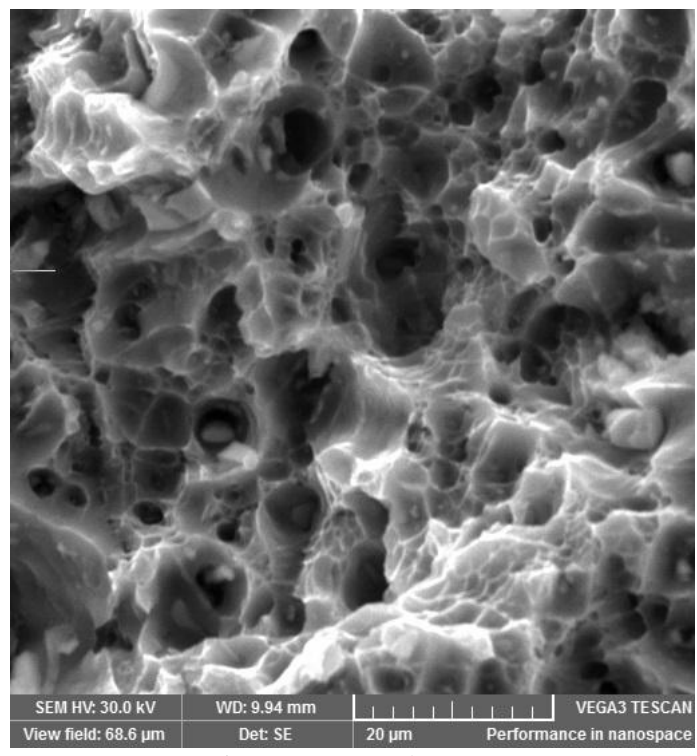

Fig. 19 Sample OK

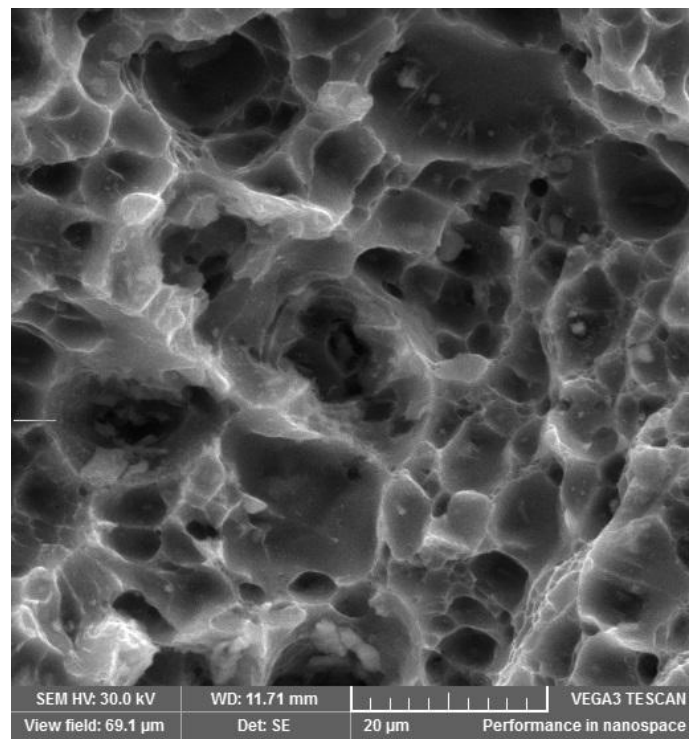

Fig. 20 Sample NOK

\section{Discussion}

When comparing measured values after measuremet by spectrometric analyses, there was found that the chemical composition of individual elements (for samples OK and NOK) is within the tolerance values of the standard CSN EN 573-3, which means that the chemical composition corresponds to this standard for both rods.

When comparing the mechanical properties (tensile test) for the sample OK and NOK, there were found the higher breaking strength for the sample OK, and higher ductility on the same sample. Higher was also measured the proof strength. Sample OK thus exhibited better mechanical properties than the sample NOK.

When comparing a sample $\mathrm{OK}$ and NOK after microscopic analyses using light microscopy in longitudinal section, there can be observed diversity in the size of intermetallic phases. In sample OK can be observed large intermetallic phases, which are uniformly spaced and are approximately $50 \mu \mathrm{m}$. In sample NOK, the phases are smaller and irregularly distributed. Their size was about $30 \mu \mathrm{m}$.

When comparing the grain size on samples (etched state) OK and NOK there was possible to observe the difference in grain size. In sample OK could be observed finer grains than in sample NOK. Because the grain size also affects the machinability of aluminum alloys may be assumed that the sample OK is better machinable.

According to the results of EDX analysis, for sample OK, there was an intermetallic phase based on $\mathrm{BiAlMg}$ with major share of Bi. Oxygen and carbon in this particle found as impurities. Due to the large proportion of $\mathrm{Bi}$ we can say that these particles could have a significant positive effect on the machinability of this alloy. The size of this particle was about $10 \mu \mathrm{m}$. The second analyzed particle being by chemical composition, size and shape similar to the first particle but there had a higher proportion of $\mathrm{Bi}$. The size of this particle was also about $10 \mu \mathrm{m}$. The third particle was by EDX analysis characterized as polycomponent phases based on AlFeSiMg.In sample NOK were analyzed four particles. For the first particle, according to the chemical composition it has been possible to say that this is an intermetallic phase based on AlPbMg. The size of the first particles was approximately $4 \mu \mathrm{m}$. The second analyzed particle was identified as an intermetallic phase based on AlBiMg. This particle was also great about 4 $\mu \mathrm{m}$. Third particle had a similar chemical composition as the second particle. This was according to 
analysis the intermetallic phase based on AlBiMg. The difference, however, was on its size. This particle was approximately half the size, was great about $2 \mu \mathrm{m}$.

Next samples were machining. For roughing the roughness was slightly better for the alloy NOK, when finishing the surface roughness was either the same or slightly better for the alloy OK.

The chip for OK and NOK was always small, crumbly, arched. There were observed only small differences in the size of the chip for each cutting conditions.

For number of chips per $100 \mathrm{~g}$ graphs were confirming the fact gathering already in evaluating the shape of the chips. Better in this measurement strangely again based alloy NOK.

For stamping chip coefficient was followed that during both cutting speeds occurred in samples OK to higher stamping chip, thus a higher plastic deformation of the chips.

The difference in hardness values may be stated due to lower copper content in sample NOK. The hardness difference between samples was insignificant and therefore it would not have a significant effect on machinability of both samples OK and NOK.

On the base of fractographic analysis may be stated that it was a breach of ductile pit morphology For both, OK and NOK, in fractures there were particles of various sizes, on the sample OK, however, they were larger. For both samples particles were cohesively connected with the matrix, the matrix was during the loading in the area of occurrence of particles considerably plastically deformed. For samples there was not brittle failure of particles. On the fracture surfaces were observed defects of metallurgical origin (oxide films, porosity) that when loading to initiate the formation of cracks.

\section{Conclusion}

Based on demand were assessed two batches of one alloys, and one of them was returned in the complaint, because when it machining created very long and therefore unsuitable chip. There were carried out several analyzes to determine the possible causes of making inappropriate chips.

The first was an analysis of the chemical composition of samples and comparison of the chemical composition according to ČSN EN 573-3 for this alloys. It was found that the individual elements for the samples OK and NOK correspond to the chemical composition of which is determined by this standard. Further analysis was to evaluate the microstructure using light and electron microscopy, where differences were found between the samples OK and NOK structure. The principal difference was the size of grains in the samples, and the size and chemical composition of individual intermetallic phases between samples. In sample OK occurred larger particles based on $\mathrm{Al} \mathrm{Mg}$, which have a positive effect on the machinability of the alloy. The size of these phases was approximately $10 \mu \mathrm{m}$. Sample NOK contained intermetallic phases based on AlBiMg that were smaller in size (approximately $4 \mu \mathrm{m}$ ). These intermetallic phases have a lower content of $\mathrm{Bi}$. In sample OK were these phases more uniformly spaced than in sample NOK. In terms of the microstructure can be concluded that the sample OK has better machinability due to the smaller grain size, more uniform spacing of intermetallic phases, preferably the chemical composition of these phases because of the higher content of $\mathrm{Bi}$ and a larger size of these phases.

Although shown difference in microstructure, during roughness measurement and evaluation of the chips after the machining has not been demonstrated different machinability of the alloy at the laboratory selected cutting conditions. The findings, which were found to show that changing the cutting parameters can be achieved good machinability as well as for NOK sample, although there has been some change of microstructural parameters. Another recommendation is from the customer to specify further requirements on the microstructure of alloys machined as e.g. grain size, phase separation etc. 


\section{Acknowledgement}

Authors are grateful for the support of grant CZ.1.05/4.1.00/11.0260.

\section{References}

[1] Vojtech, D.Metallic materials. VSCHT Praha, Praha, 2006, 140 p.

[2] Michna, S.,Kusmierczak, S. Practical metallography OPTYS, FVTM UJEP, Ústí nad Labem, 2012, $245 \mathrm{p}$.

[3] Bruker Q4 TASMAN - the "Multi-Tool" in Metal Analysis [online] 2016 [cit. 3. 5. 2016]. Available from <http://trends.directindustry.com/bruker-elemental-gmbh/project-30028124882.html>.

[4] Kalincová, D. Testing of mechanical properties of materials - overview of metering methods and equipment. In Increasing the efficiency of the educational process. KEGA 3/6370/08., TU voZvolene, Zvolen., 2010, p. 13-26.

[5] Michna, S.,Naprstkova, N. TheMechanicalPropertiesOptimizingofof Al - Si AlloysPrecipitationHardening and theEffect on theCharacteroftheChip. In Acta MetallurgicaSlovaca, No. 3, 2011.

[6] Kusmierczak, S. TheUsageofConfocal Laser Microscope by SolvingStudentsProjects, In proceedingsof International MiltidisciplinaryConference, 2011, Nyíregyháza, Hungary, 2011, p.149-152.

[7] Weiss, V. Hodnoceni vlivu teploty a doby homogenizačnihožihani slitiny AlCu4MgMnz hlediska mikrostruktury, obrazoveanalyzy a metody EDX. In Strojirenska technologie, Vol. 17, No. 5,6, 2012, p. 348-355.

[8] Weiss, V.,Strihavkova, E. Influence of the homogenization annealing on microstructure and mechanical properties of $\mathrm{AlZn} 5,5 \mathrm{Mg} 2,5 \mathrm{Cu} 1,5$ alloy. In Manufacturing Technology, Vol. 12, No. 12, 2012, p. 297-302.

[9] Czajkowska, A., Kossakowski, P., Wcislik, W., Stasiak-Betlejewska, R. Application of Electron Scanning Microscope in the Analysis of the Structure of Casting Non Conformities Aimed at Optimization of Technological ProcessParameters. In Manufacturing Technology. Vol. 13, No. 2, 2013, p. 164-169, ISSN 1213-2489.

[10] Weiss, V., Svobodova, J. The Use ofColourMetallography and EDS forIdentificationofChemicalHeterogeneityofSelected Aluminium AlloysCopper and ZincAlloyed. In Manufacturing Technology, Vol. 15, No. 6, 2015, pp. 1048-1053. Czech Republic

[11] Cais, J. Elektronova mikroskopie. Metalografie, CZ.1.07/2.3.00/45.00 29, [online], 2015 [cit.14.5.2016]. Available from:

<http://www.csvs.cz/projekty/2014_veda_pro_zivot/data/11_KA3_Jaromir_Cais_2_Elektronova_ \%20mikroskopie_a_\%20EDS_\%20analyza_metodicka_prirucka.pdf.> ISBN 978-80-86302-67-6.

[12] Poková, M., Cieslar, C. Microstructure Evolution of Al-Mn-Si-Fe Alloy Studied by In-situ Transmission Electron Microscopy. In Manufacturing Technology, Vol. 14, No. 3, 2014, pp. 412417, ISSN 1213-2489

[13] Valicek, J., Rusnak, J., Muller, M., Hrabe, P., Kadnar, M., Hloch, S., Kusnerova, M. Geometric aspects of surface roughness of classic and non-traditional technologies. In Jemna mechanika a optika, Vol. 53, No. 9, 2008, p. 249-253.

[14] Hricová, J. Influence ofCuttingToolMaterial on theSurfaceRoughnessofAlMgSi Aluminium Alloy. In Manufacturing Technology, Vol. 13, No. 3, 2013, p. 324-329.

[15] ISO 3685 1993. Tool-lifetestingwith single-point turningtools.

[16] Valasek, P. Muller, M. Picture AnalysisofFailureAreasofParticleComposites. In Manufacturing Technology Vol 14, No 3, 2014, pp. 474-478. Czech Republic. 